\title{
Innovations in Physics Education: Impact of Inquiry-based Laboratory Format on Students' Perceptions and Learning Gains*
}

\author{
Tracy Cator-Lee, Mary Ewell \\ George Mason University, Virginia, USA
}

\begin{abstract}
Updating physics laboratory instruction through implementation of an inquiry-based (IB) format is a popular approach to modern physics education. Increasingly physics education research (PER) is being utilized to improve the overall quality of physics instruction. As growing numbers of instructors switch from traditional to IB methods, it is crucial that the impact on students be examined. In 2013, George Mason University (GMU) began offering their second semester calculus-based Physics 261 laboratories in both IB as well as traditional format. To gauge students' perceptions of these two distinct styles, a 17-question self-assessment consisting mainly of Likert questions (scale of 1-6) was created and administered to students near the end of the Spring 2015 Semester. In addition, students completed the Brief Electricity and Magnetism Assessment (BEMA) at the beginning and again at the end of the semester. Self-assessment question responses were grouped into two categories, generally positive and generally negative, and pre- and post- scores for the BEMA were analyzed using the average normalized gain factor. Overall, the IB students had more positive (self-assessment) responses. Although IB students had higher gain factors, BEMA scores for both classes were generally low and standard deviations (STDEV) were high. Potential benefits and drawbacks of the IB format were discussed along with results, analysis, and the need for continued research.
\end{abstract}

Keywords: physics education research (PER), inquiry-based (IB), guided inquiry, physics laboratory, assessment

\section{Introduction}

Physics education is undergoing a transformation; a paradigm shift from traditional teaching styles to interactive-engagement, activity-based, and inquiry-based (IB) methods (Cahill et al., 2014; Pollock \& Finkelstein, 2014; Thacker, Dulli, Pattillo, \& West, 2014; Yoder \& Cook, 2014; Lindsey, Hsu, Sadaghiani, Taylor, \& Cummings, 2012; Etkina, Murthy, \& Zou, 2006; Hake, 1998). This change is based on a continually expanding body of research, which supports the hypothesis that more "hands-on" and interactive approaches, such as IB physics instruction, improve students' understanding and retention of physics concepts. Ability to

\footnotetext{
*Acknowledgments: We would like to thank the George Mason University Physics and Astronomy Department and acting director, Dr. Maria Dworzecka, for funding our research through a grant from 4VA and the George Mason University Undergraduate Research as Scholars Program and director, Dr. Rebecca Jones, for the stipend awarded for this project, and finally, our assistant Ayabavi Tournouvi, for all of her time and effort grading assessments and analyzing results.

Tracy Cator-Lee, B.S. in Physics, student researcher, Department of Physics and Astronomy, George Mason University.

Mary Ewell, Doctor of Physical Sciences, term associate professor, Department of Physics and Astronomy, George Mason University.
} 
think conceptually and make connections between concepts learned in physics and other areas of study is key to demonstrating genuine understanding (Lindsey \& Nagel, 2015; Plomer, Jessen, Rangelov, \& Meyer, 2010; McDermott, 2001). Research is being carried out not only for college and high school students, but for instructors (including K-8) of all levels as well (Gaffney, 2013; Eylon \& Bagno, 2006). Instructional formats for both lecture classes and laboratory classes are being altered. It is imperative the physics education research (PER) takes a comprehensive view of the growing data and examines not only the positive, but also the potential negative impact of these innovations (Eylon \& Bagno, 2006; McDermott, 2001; Hake, 1998).

\section{Literature Review}

Some instructors and students alike are simply resistant to change, or find new methods too "open-ended"; grading an IB lab report is more subjective and time-consuming than grading a traditional one, and creating an IB lab is more complicated than following step-by-step instructions (Thacker et al., 2014). Despite these concerns, popularity of the IB format continues to increase. A considerable body of research has also been conducted for chemistry and biology IB students (Brickman, Gormally, Armstrong, \& Hallar, 2009; Deters, 2005; Sundberg, Armstrong, \& Wischusen, 2005; Sundberg \& Armstrong, 1993). While all IB laboratory classes have common elements, there are differences. The conceptual complexity of the subject matter can be particularly challenging for physics students, especially during the second semester, when electricity and magnetism (EM) is the main focus. To accurately assess their perceptions and learning gains, two key elements are necessary: (a) collection of student feedback through self-assessment, focus groups, or individual interview; and (b) assessment of knowledge and skills through written or practical exams or exercises (Lindsey \& Nagel, 2015; Zwicki, Hirokawa, Finkelstein, \& Lewandowski, 2014; Thacker et al., 2014; Ding, 2014; Ding, Chabay, Sherwood, \& Beichner, 2006; Seymour, Wiese, Hunter, \& Daffinrud, 2000). Additionally, the importance of ensuring an adequate (and current) knowledge base for instructor's, their ability to assess students' levels of comprehension and explain concepts in a meaningful and productive way has been illustrated (Eylon \& Bagno, 2006). There are many facets of PER that need to be addressed; from alerting instructors to the vast body of current PER, the import of peer interaction, and social concerns, such as racial and gender gaps. While numerous factors contribute to the overall quality of physics education, we focus here on the potential benefits of new instructional methods.

There are several new instructional methods, such as Active Physics, currently being implemented. The common element to all these, whether in lecture or laboratory, is student involvement; students are engaged in doing activities, generating questions, and experimenting to discover answers for themselves (Yoder \& Cook, 2014). Learning is no longer a passive activity but an active one. By allowing students freedom to explore, it is hoped they will enjoy learning, and retain more conceptual knowledge (Zwicki et al., 2014). In an effort to contribute to laboratory-focused PER, student assessments were administered during the Spring 2015 Semester at George Mason University (GMU). Traditional lecture students had a choice between the traditional and IB instructional methods for laboratory class. Students who choose the alternative lecture (which required student involvement and took a more interactive approach than traditional lecture class) were required to register for the IB lab class. A total of 117 students completed the self-assessment and requisite consent form, 65 from the traditional class and 52 from the IB.

A true IB laboratory class replicates the way physicists actually carry out research, this would be inappropriate for introductory students, who are still learning the fundamentals of experimentation. To help IB 
students avoid the pitfalls of confusion and erroneous conclusions, a guided inquiry approach was implemented (Etkina et al., 2006; Deters, 2005; Hake, 1998). Guided inquiry is a particular type of IB laboratory in which students are given a subject, e.g., Ohm's Law, and some questions they might want to answer (How does adding resistors in a series circuit change the potential difference? What about in a parallel circuit?), they are given access to equipment, in this case, multimeters, resistors, breadboards, and banana wires, and asked to design and carry out their own experiment. Instead of following rigid instructions and arriving at a predetermined conclusion, a student may be surprised to find that while resistors add in series, they add in reciprocal in parallel. This is a basic fact of EM, but the act of discovering vs. simply being told "it is so," likely increases the impact this has on a students' perception. With this premise in mind, all Physics 261 students were given the BEMA; designed as a tool for measuring introductory students' conceptual knowledge of EM, BEMA is purported to be a useful component of PER (Ding, 2014; Pollock \& Finkelstein, 2014; Ding et al., 2006). Results for this study (for various reasons discussed below) were not as conclusive as hoped for, but certainly substantial enough to warrant further research.

\section{Methods}

During the Spring 2015 Semester at GMU, a total of seven sections of Physics 261 were offered, four in the traditional format and three IB. Class sizes ranged from 12 to 24 . Physics 261 is a second semester calculus-based laboratory class that is taken in conjunction with Physics 260 lecture class. The main focus of these classes is EM. For many students, this is their first introduction to the subject; topics include Coulomb's Law, Ohm's Law, Series and Parallel circuits, and electric and magnetic induction. Regardless of instructional method, Physics 261 is an inherently challenging class for students. This creates a two-fold challenge for instructors, who must help students understand a subject that can be counterintuitive, and simultaneously promote the value and utility of physics experimentation. Students on the other hand are less likely to appreciate the relevance of the material being taught if they are struggling to understand it, and in this case they are unlikely to experience either positive perceptions or learning gains.

\section{Student Perception Self-Assessment}

There are several factors that contribute to a students' overall perception of a classroom experience. In an effort to explore students' interest level, impression of instructional methods, perceived level of comprehension, study habits, and academic ability, we designed a brief 17-question self-assessment. The assessment was structured based on the Student Assessment of Their Learning Gains (SALG) format (Seymour et al., 2000). SALG is a respected tool for student self-assessment, however, when it was utilized during the Fall 2014 Semester, participation rates for weekly assessments were only $50 \%$ (despite the fact that extra credit was offered per each completed assessment). In an effort to achieve maximum student participation, a custom survey was printed out and administered during laboratory class. Students received a small extra credit incentive for completion of the survey. Ideally, both a pre- and post- assessment would have been given, however, time constraints allowed for only a final assessment during this semester.

In reflection of the SALG format, our survey was presented to students in four sections: (a) "Presently I can"; (b) "Presently I am"; (c) "I am in the habit of"; and (d) "Currently in my academic career" (for complete student self-assessment, see Appendix). For analysis, questions were reorganized into four categories: (a) skills; (b) learning gains; (c) academics; and (d) perceptions (see Table 1). Likert questions offered a scale of 1-6 to 
allow students a sufficient range of choices. The even number of selections had the added benefits of avoiding a possible middle value and allowing for answers to be grouped into two main categories: generally positive (4-6) and generally negative (1-3). Short answer questions were grouped in a similar way, and an agreement of at least $85 \%$ was reached on categorization.

Table 1

Categories Used to Analyze Self-Assessment Questions

\begin{tabular}{ll}
\hline Category & Question \\
\hline Skills & $1,2,3$, and 4 \\
Perceptions & $7,8,9$, and 16 \\
Learning gains & $5,6,12$, and 17 \\
Academics & $10,11,13,14$, and 15 \\
\hline
\end{tabular}

\section{Brief Electricity and Magnetism Assessment (BEMA)}

To measure students' learning gains, the BEMA was administered, during lecture class at the beginning of the semester, and during lab class at the end of the semester (Ding, 2014; Ding et al., 2006). Students did not receive extra credit for completion of this assessment as it was administered as part of the curricula, to help lecture professors gauge student progress. This comprehensive electricity and magnetism assessment consists of 31 questions, with a total of 30 possible points according to suggested scoring instructions (Ding et al., 2006). In the post assessment, we omitted four of the questions; seven and eight for lack of clarity, and 13 and 30 in the interest of brevity. The remaining 27 were then compared to the initial 27 responses on a student-by-student basis. Pre- and post- tests (with student names) were not available for all students, only 21 traditional and 32 IB EM assessments were analyzed using the normalized gain factor (Yoder \& Cook, 2014; Brickman et al., 2009; Bao, 2006; Hake, 1998). Because a large sample size of post BEMA tests $(N=98)$ were available, further analysis was performed to examine how many students correctly answered individual questions, as well as student performance in particular concept areas (results, brief electricity, and magnetism assessment).

\section{Results}

\section{Student Perception Self-Assessment}

The four questions that asked students about skill development (see Figure 1) illustrate abilities in wiring simple circuits, working with excel, writing a lab report, and formulating problem-solving strategies. The graph clearly shows that IB students responded with higher percentages of generally positive answers to all questions. It should be noted that question 3 which asked students to provide five essential elements of a lab report was scored differently than the others. Student responses that correctly listed four or five elements of a lab report counted as generally positive, and responses with less than four correct (including no response) were counted as generally negative. Both groups performed poorly (less than 50\%) on question 3 . The question of greatest interest here, question 4 , which asks about developing an effective problem-solving strategy, yielded $11 \%$ more positive responses from IB students.

Student perceptions (see Figure 2) were all more positive for IB students than traditional students. However, both scores were below $50 \%$ for question 7 , which asks about enthusiasm in completing experiments. Students' confidence in their experimental abilities (question 9) was $13 \%$ higher among IB students, and IB students' overall impression of the class (question 16) was a significant $27 \%$ more positive than traditional students'. 


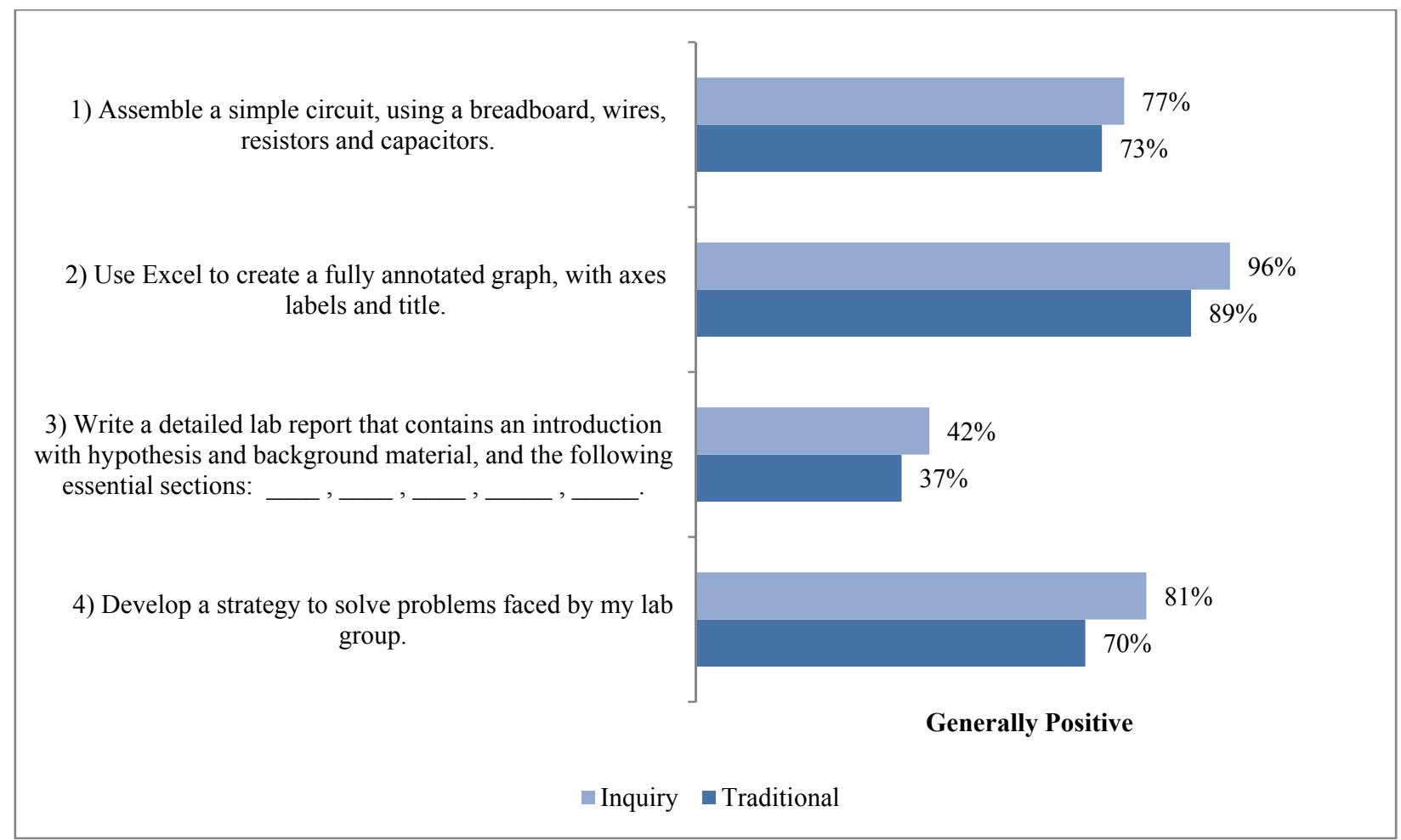

Figure 1. Skills. Students' confidence in their abilities: Wiring a breadboard, working with Excel, writing a lab report, and developing problem-solving strategies. The percentage of students whose answers were generally positive (Likert scale 4-6), are shown for both IB and traditional classes.

7) Enthusiastic about constructing experiments in my physics lab class.

8) Comfortable asking my instructor or TA questions during lab class.

9) Confident in my ability to successfully complete all lab experiments in this course.

16) My overall impression of this class is:

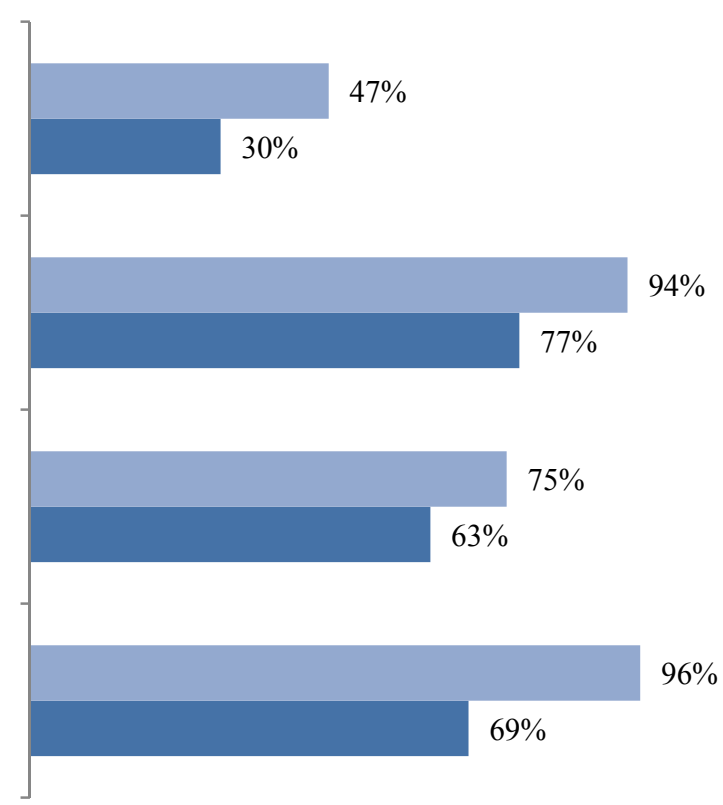

Generally Positive

Figure 2. Perceptions. Students' enthusiasm, level of comfort interacting with teacher and/or teaching assistant, confidence levels, and overall impression of the class. 


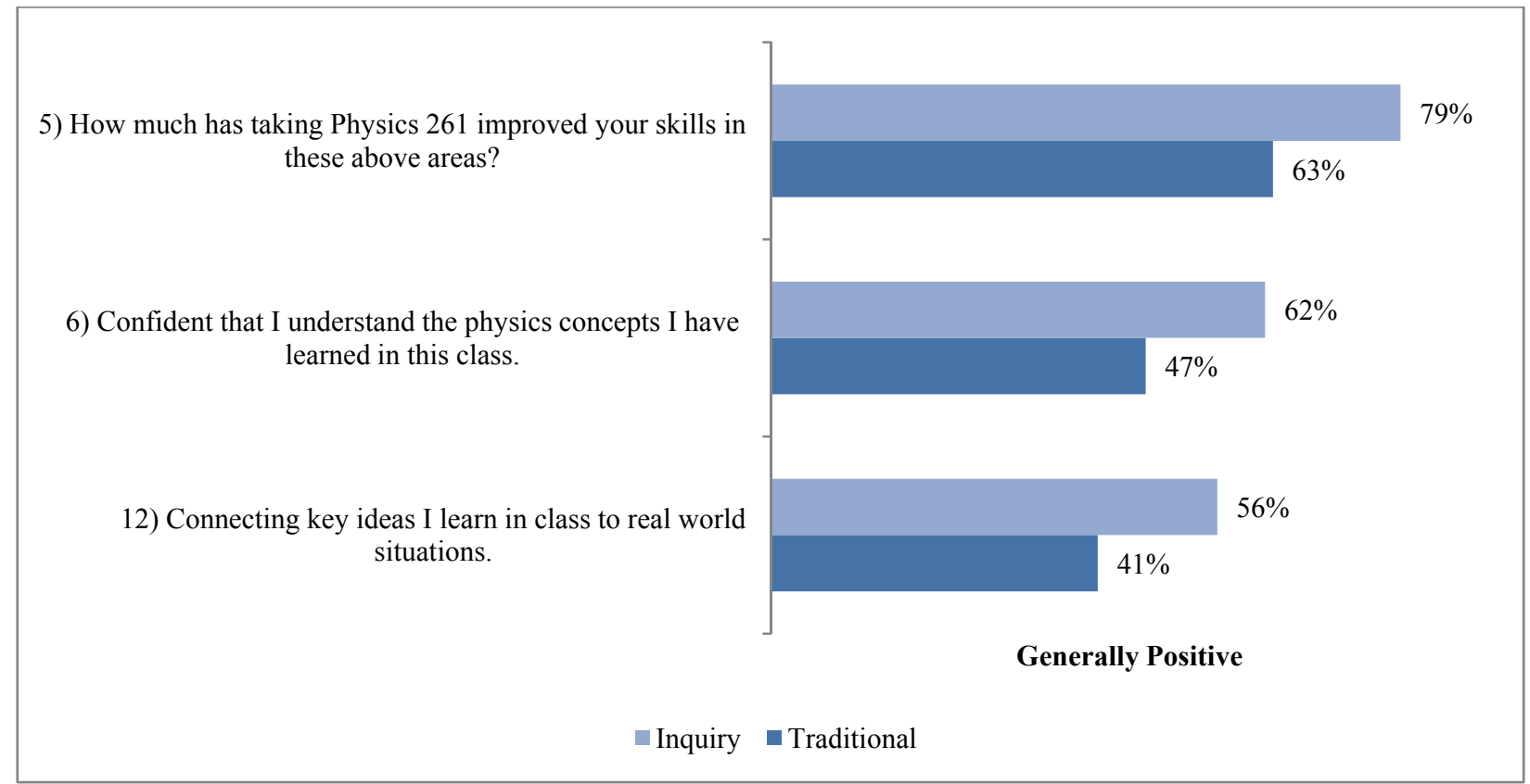

Figure 3. Learning gains. The percentage of students who feel that Physics 261 improved their skills (as defined in Figure 1), improved their understanding of physics concepts and their ability to connect ideas from class to real world situations.

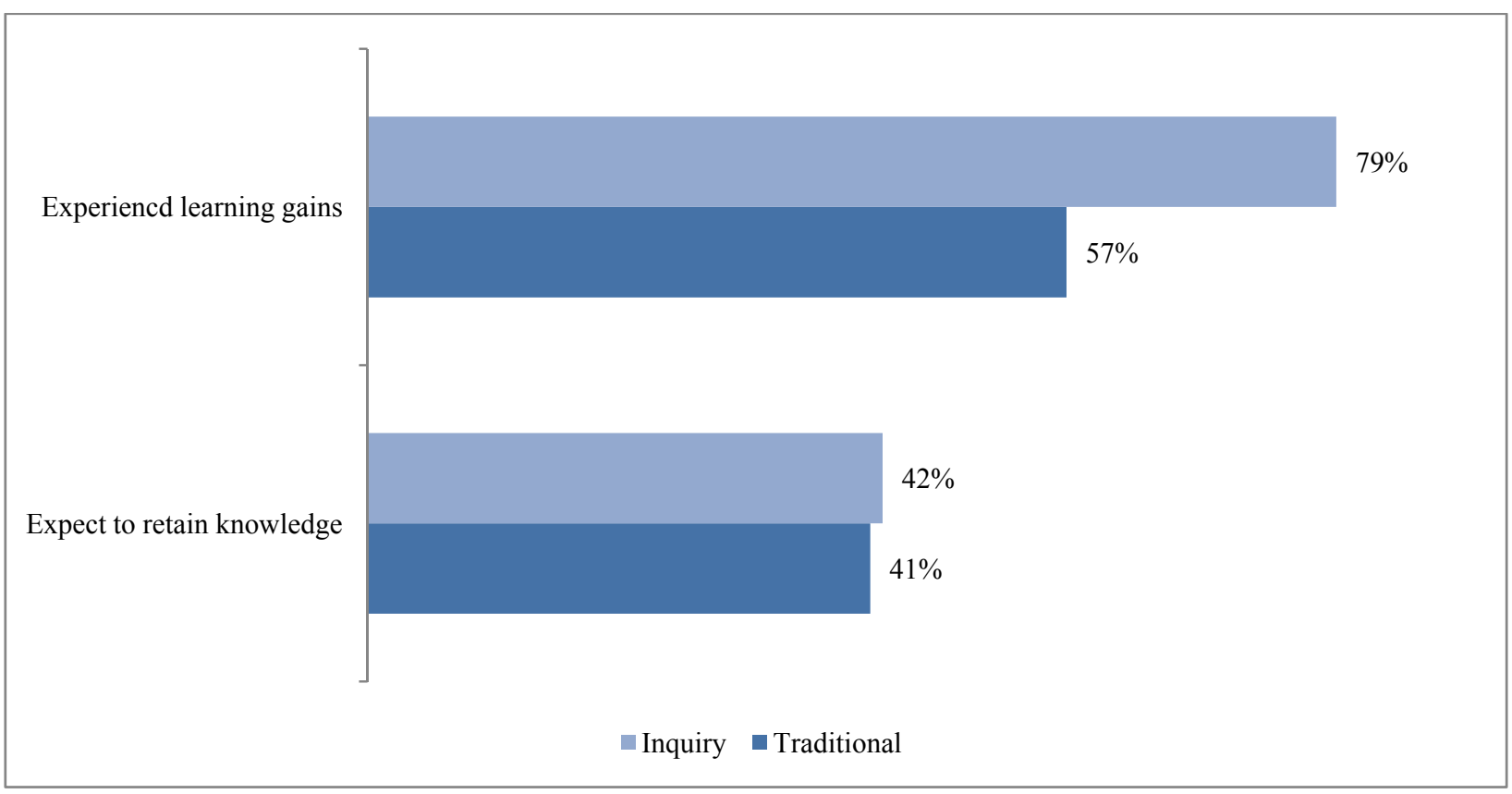

Figure 4. Learning gains, question 17. The percentage of students who expressed the intention to retain knowledge learned in Physics 261, and those who stated they learned something from the class. These percentages are based on the number of relevant responses (students who did not respond or who wrote "No response" were not included), $N=38$ for IB, and $N=37$ for traditional. The author's agreed to greater than $85 \%$ on the categorization of responses.

The three Likert scale learning gains questions are displayed in Figure 3, while question 17, which was a two-part short answer question, is displayed in Figure 4. At a glance, Figure 4 suggests that IB students experienced more learning gains; however, this short answer question had a much lower response rate than the 
Likert questions, $29 \%$ of IB and $42 \%$ of traditional students did not respond. Although $79 \%$ of IB students felt that Physics 261 improved their skills, only 62\% were confident they understood the relevant physics concepts, and only $56 \%$ were in the habit of connecting what they learned in class to real life situations. The traditional students scored poorly in all learning gains categories; only 63\% said Physics 261 improved their skills, and less than half ( $47 \%$ and $41 \%$ respectively) felt they understood the concepts or made connections with everyday life.

Academic questions concerning study habits, Grade Point Average (GPA), and choice of laboratory class are illustrated in Figure 5, while students' academic majors are detailed in Table 2. Students with GPA's 3.1 or above were fairly equally matched with $67 \%$ IB and $68 \%$ traditional. Approximately, $50 \%$ of students for both sections worked on assignments at least 24 hours in advance, but $19 \%$ more of IB students read materials prior to coming to class. There is a very substantial difference in the amount of students who specifically choose the IB class, $54 \%$, and those who specifically choose the traditional class $22 \%$. It is clear from Figure 6 that there were no significant differences in percentages of academic majors between the traditional and IB classes; variances were all less than $6.0 \%$.

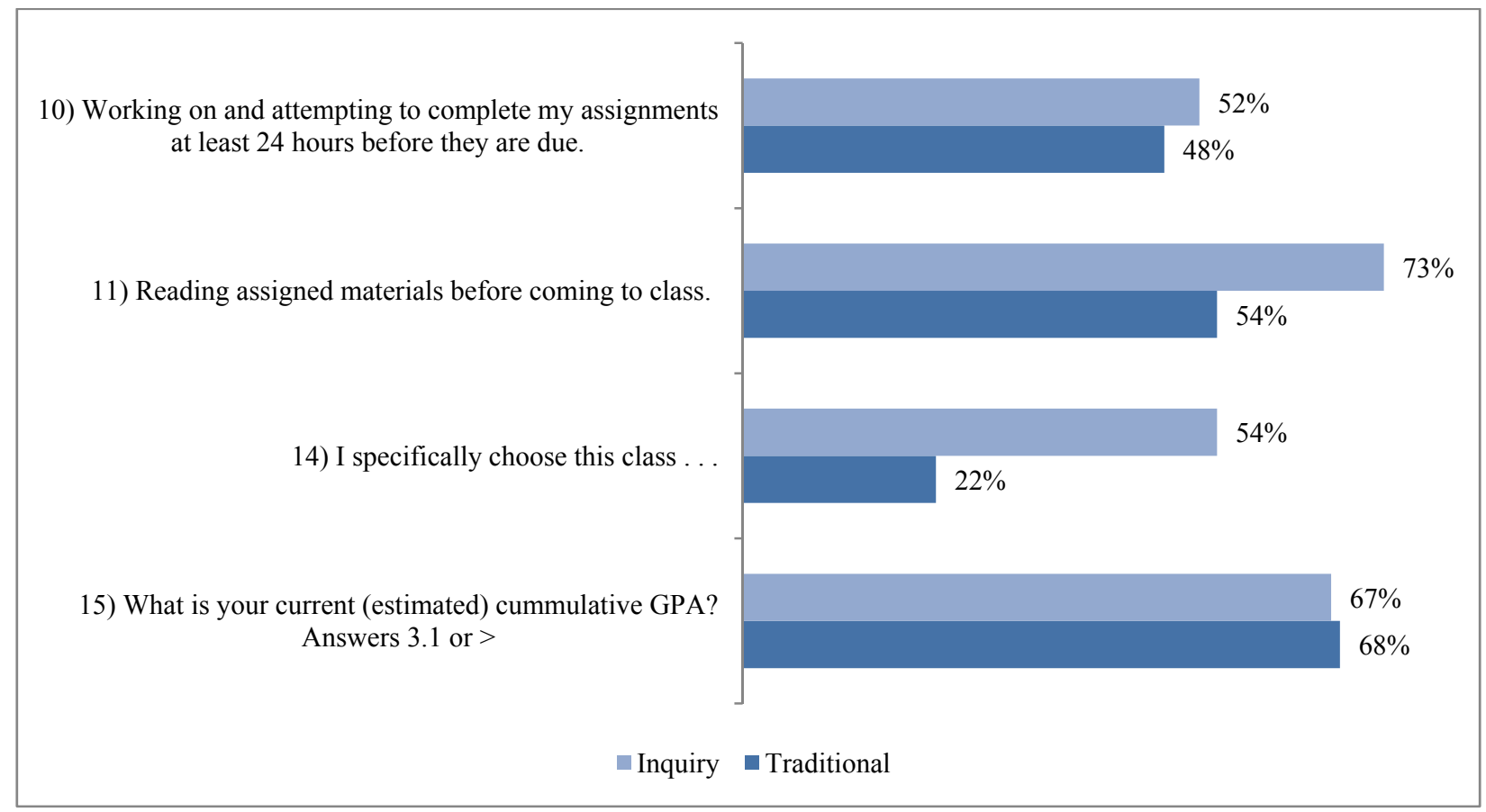

Figure 5. Academics. Students' study habits, level of preparation for class, GPA, and preference for lab class.

Table 2

Students' Choice of Academic Major

\begin{tabular}{lcc}
\hline Academic major & Traditional (\%) & Inquiry (\%) \\
\hline Physics & 6.0 & 12 \\
Math & 5.0 & 10 \\
ECE or Bio Engineer & 39 & 35 \\
Civil or systems engineer & 32 & 29 \\
Other area of science & 17 & 14 \\
Other area of non-science & 2.0 & 4.0 \\
\hline
\end{tabular}




\section{BEMA}

Positive gain factors for both classes are presented in Figures 6 and 7; clearly, IB students in the sample performed better than traditional students. Overall, however, gain factors were low; only eight IB students $(25 \%)$ and two traditional students $(10 \%)$ achieved a gain factor greater than $25 \%$. Further, the average gain factor for traditional students was $2.0 \%$ with a STDEV of $23 \%$, while the average IB gain factor was $16 \%$ with a STDEV of $20 \%$. These significant STDEV's yield a gain factor range from $-21 \%$ to $25 \%$ for the traditional classes and $-4.0 \%$ to $36 \%$ for IB. Restricting analysis to only positive gains (see Figures 6 and 7) still yields inconclusive values; traditional classes have a positive gain average of $15 \%$ with a STDEV of $9.0 \%$ and IB students have a positive average gain of $22 \%$ with a STDEV of $16 \%$. Looking at average pre- and post- scores (see Table 3), it is clear that BEMA scores were consistently low for both traditional and IB students. Since sample size was limited to $32 \%$ for traditional and $62 \%$ for IB and gain factors were low with high STDEV for both classes further analysis was performed on all $98 \mathrm{EM}$ post assessments.

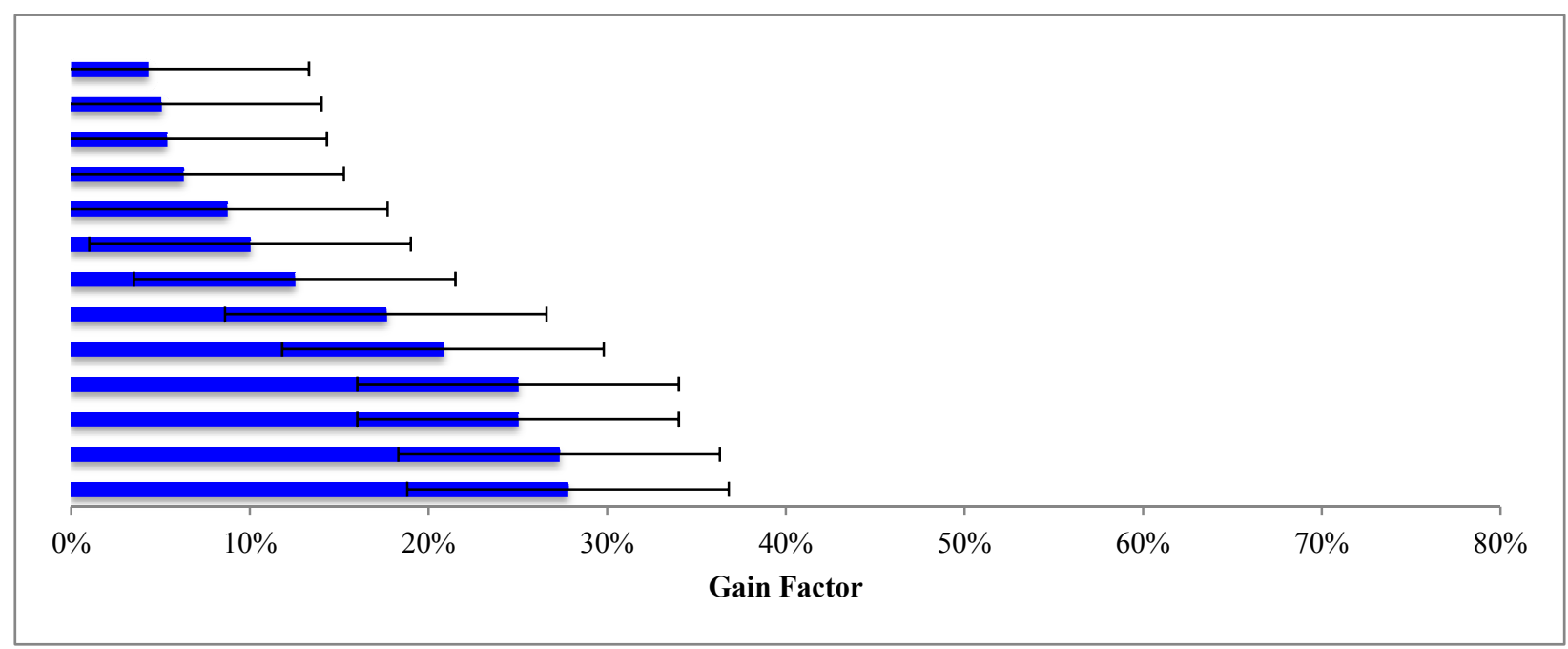

Figure 6. Positive gain factors for traditional students $(N=13)$.

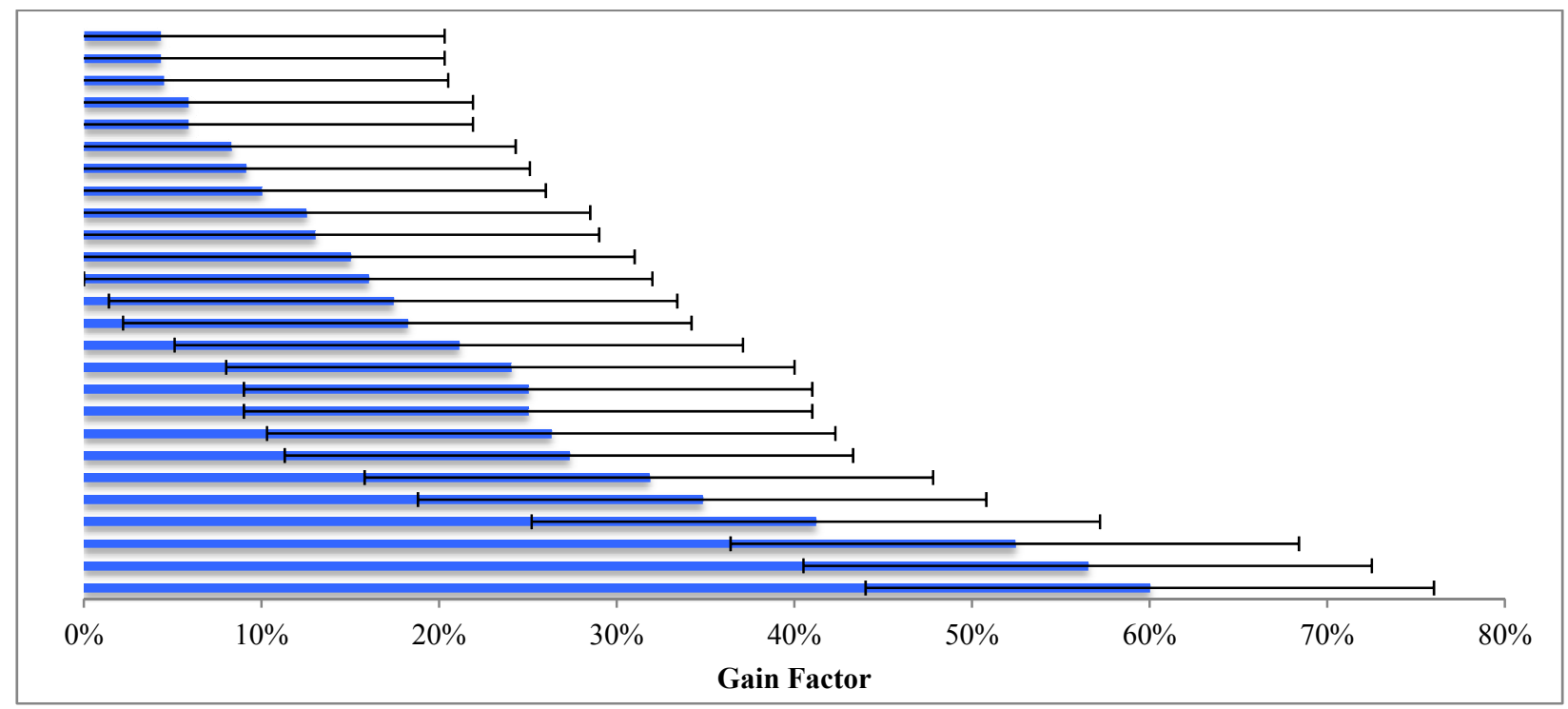

Figure 7. Positive gain factors for IB students $(N=26)$. 
Table 3

Average Pre and Post BEMA Scores With STDEV $(N=21$ for Traditional Students and $N=32$ for IB)

\begin{tabular}{lllll}
\hline & Pre & STDEV & Post & STDEV \\
\hline Traditional & $25 \%$ & $11 \%$ & $28 \%$ & $13 \%$ \\
IB & $19 \%$ & $11 \%$ & $32 \%$ & $15 \%$ \\
\hline
\end{tabular}

To explore the particular gaps in conceptual learning gains for the entire student body, BEMA questions (from the post assessment) were grouped into the following six categories: Coulomb's Law and Newton's 3rd Law, Electric Fields and Gauss's Law, Ohm's Law and Simple Circuits, Electric and Magnetic Dipoles, the Lorentz Force Law, and Induction and Polarization. A table detailing categories (see Table 4) and figures displaying results are shown below (see Figures 8-13). Examination of these data illustrates that students failed to make significant learning gains in any of the six categories; while students performed fairly well $(40 \%$ or better) on questions that involved memorization of formulas and/or facts, they performed poorly on questions that involved deeper conceptual thinking and analysis.

Table 4

The Average Percentage of Correct Answers, for All Students Who Completed the Post BEMA (N=98), in Six Different Concept Areas

\begin{tabular}{lll}
\hline Category & Average correct (\%) & STDEV (\%) \\
\hline Coulomb's Law \& Newton's 3rd Law & 51 & 14 \\
Electric Fields \& Gauss's Law & 36 & 21 \\
Ohm's Law \& Simple Circuits & 18 & 16 \\
Electric \& Magnetic Dipoles & 25 & 14 \\
The Lorentz Force Law & 18 & 12 \\
Induction \& Polarization & 16 & 12 \\
\hline
\end{tabular}

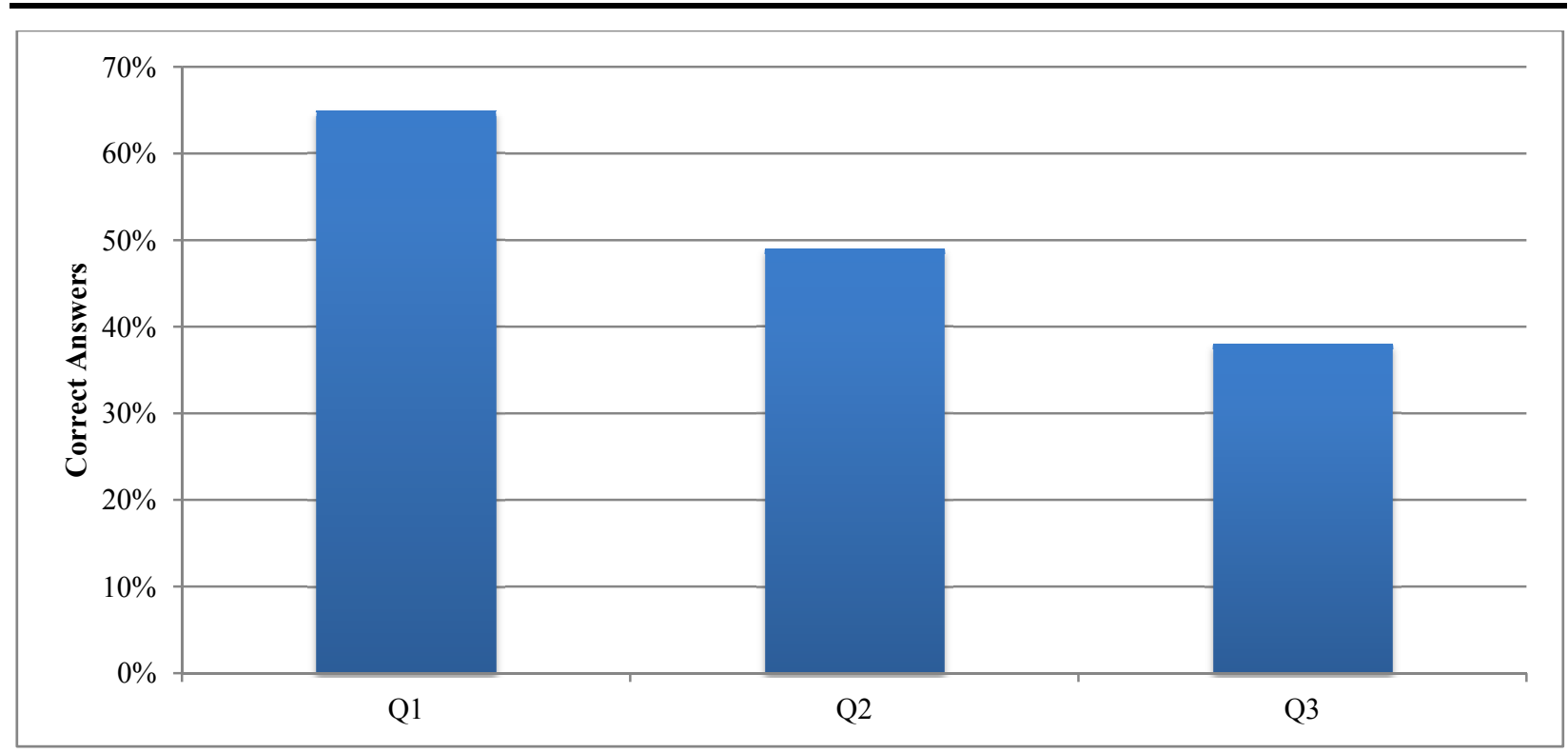

Figure 8. Coulomb's Law and Newton's 3rd Law. The percentage of students who demonstrated basic understanding of the force between two charged particles. While the majority of students correctly answered question 1 which simply required knowledge of Coulomb's Law, less than half possessed sufficient knowledge of Newton's 3rd Law to correctly answer questions 2 and 3 . 


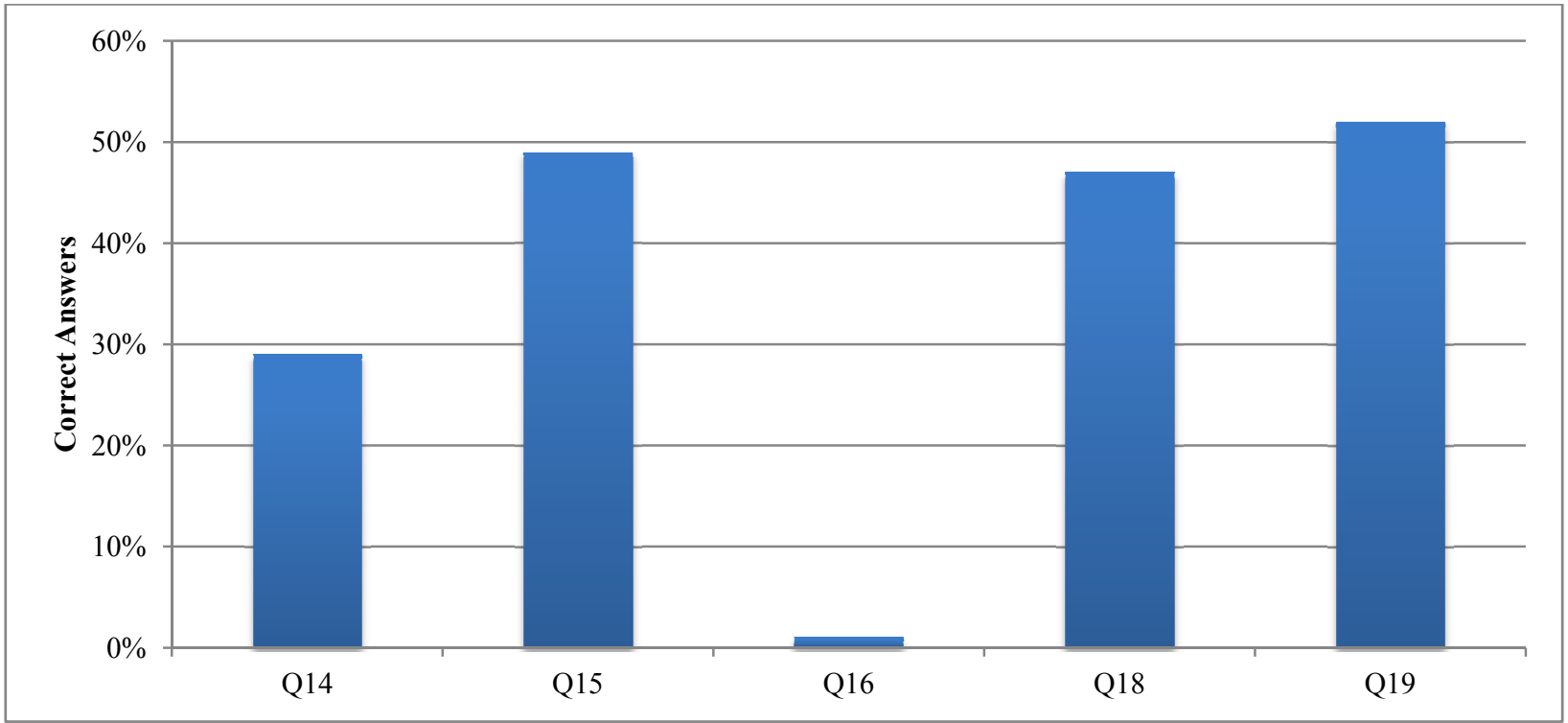

Figure 9. Electric Fields and Gauss's Law. Students' understanding of potential difference and electrical fields. Questions 14, 15, and 16 involve potential difference between points in an electric field. While only $29 \%$ of students answered question 14 correctly, another 33\% answered the correct magnitude but wrong sign for potential difference; taking these both to be acceptable answers a total of $62 \%$ of students answered well. Nearly half (49\%) of students correctly answered question 15 , which makes it surprising that only one student was able to synthesize their answers (from question 14 and question 15) to correctly answer question 16. Questions 18 and 19 respectively, dealt with the flow of an electric field and a metal in static equilibrium.

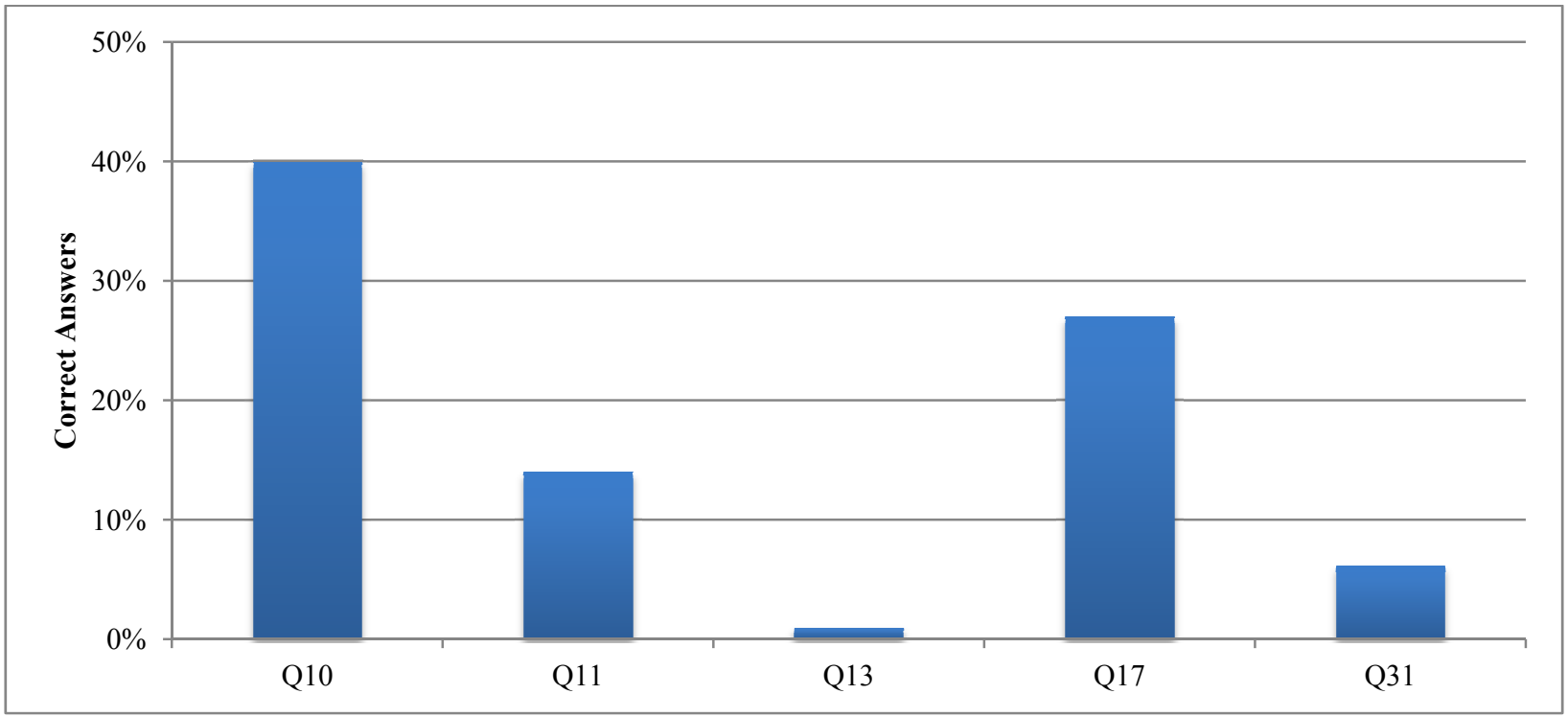

Figure 10. Ohm's Law and Simple Circuits. Students' comprehension of how current, voltage, and resistance are related in simple circuits. While $40 \%$ of students understood Ohm's Law adequately to correctly answer question 10 , the second and third most popular answers (23\% and $16 \%$ respectively) demonstrate a complete lack of understanding. Question 11 again utilized Ohm's Law, in a more complicated way, and only 14.2\% of students answered correctly. Only one student correctly answered question 13 about energy stored in a capacitor, this question required careful consideration, not simply memorization of a formula. Question 17 was answered correctly by only $27 \%$, however, since the circuit involved was "open," it is easy to see why $45 \%$ of students thought the answer should be 0 volts. Question 31, although directly related to Ohm's Law, was one of the more challenging conceptual questions on the assessment. 


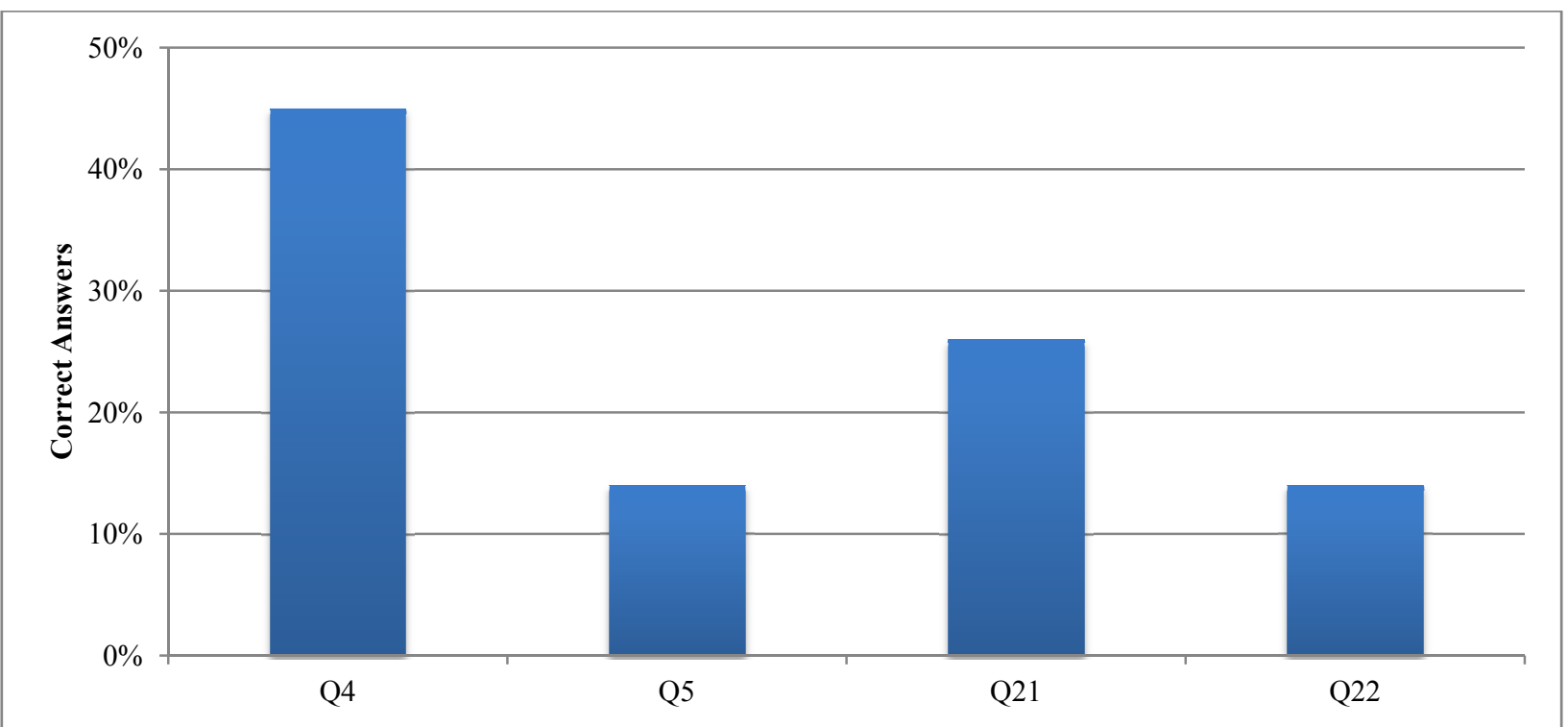

Figure 1. Electric and Magnetic dipoles. Students' conceptual understanding of how electric and magnetic dipoles work. Questions 4 and 5 both asked about field lines from electric dipoles, it is unclear why nearly half correctly answered question 4 (45\%) while only 14\% correctly answered question 5. Questions 21 and 22 were very similar to questions 4 and 5 except that they asked about field lines for a magnetic dipole.

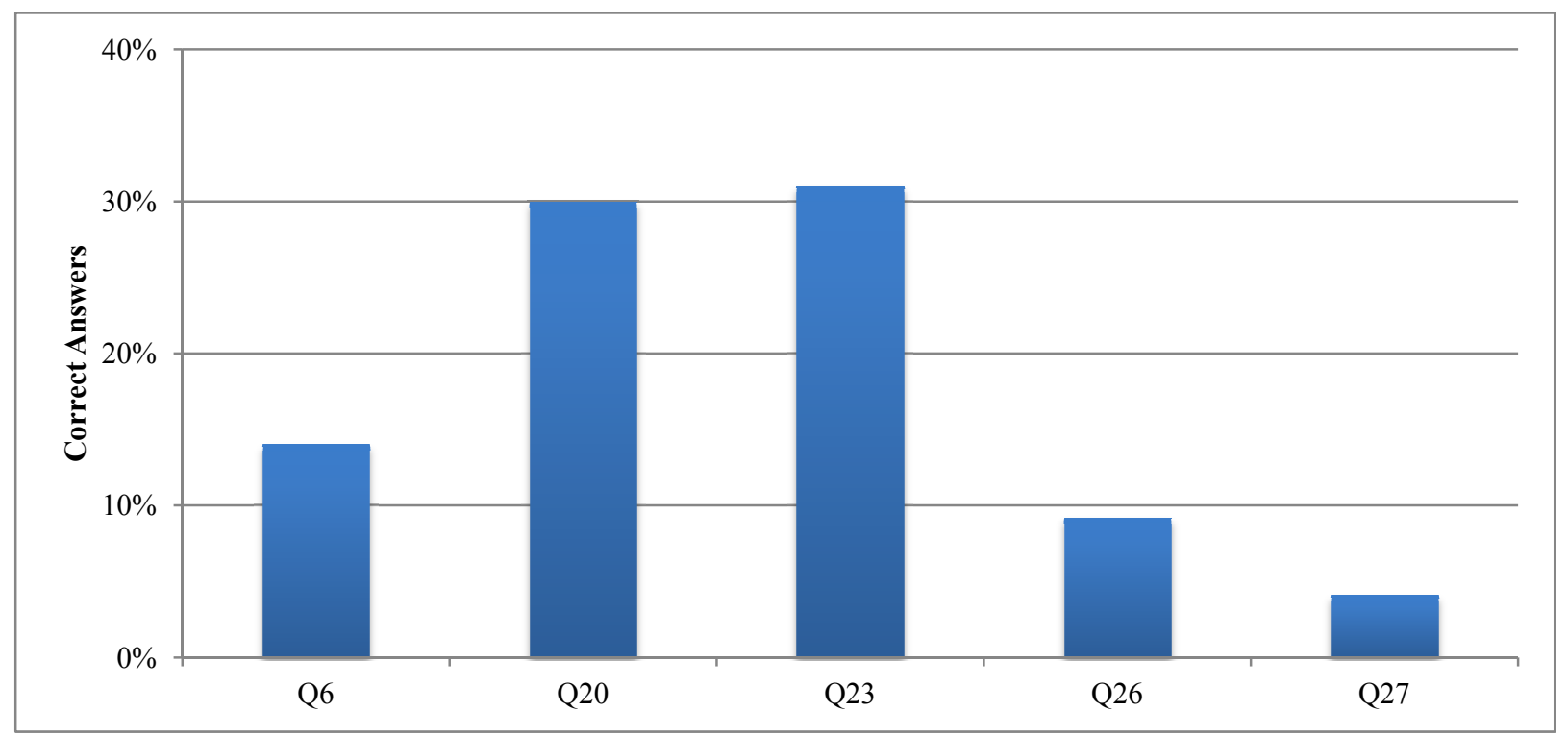

Figure 12. Lorentz Force Law. Results for question 6 were surprisingly low; students needed only to remember that electric fields flow from positive to negative or apply the Lorentz Force Law. When applying the Lorentz Force Law, however, it is easy to become confused over the sign of the charge (electrons carry negative charge); an additional $26 \%$ of students answered the opposite direction for the electric field, quite possibly because they forgot to include a negative sign in their equation. Questions 20, 23, 26, and 27 all utilize the Lorentz Force Law, although questions 26 and 27 require more careful thought. 


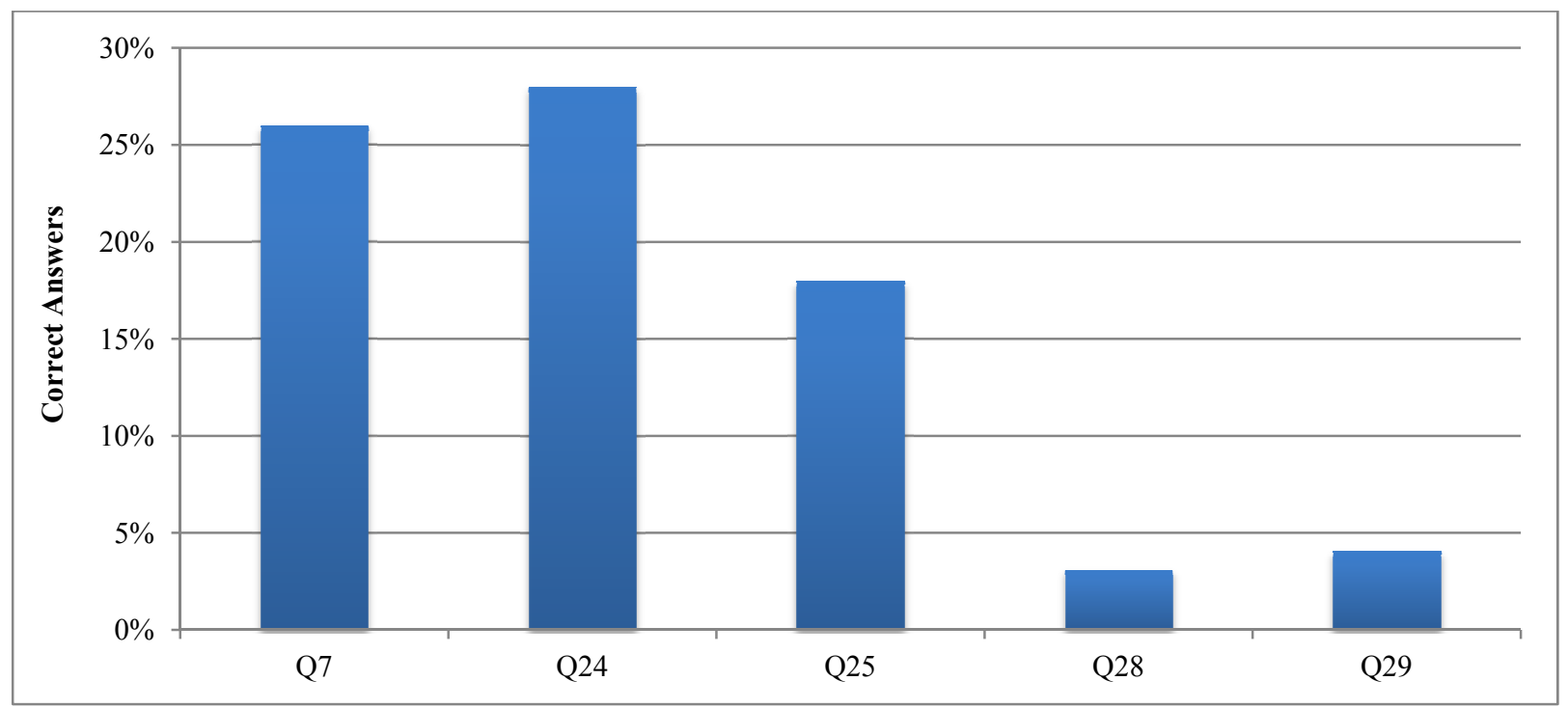

Figure 13. Induction and polarization. Question 7 is a very straightforward question about polarization, however, students may have been confused because rubber is a dielectric (insulator) not a conductor and so mistakenly concluded the rubber does not become polarized ( $40 \%$ said the rubber does not move because it is an insulator). Questions 24 and 25 deal with magnetic induction, based on the variety of incorrect answers students appeared to struggle with this concept. Likewise questions 28 and 29, which asked about electric induction, received a large variety of incorrect answers, a sign that students found the concept confusing.

\section{Discussion and Conclusion}

From the self-assessment, it is clear that IB students had a more positive laboratory experience. The vast majority (96\%) of IB students rated their overall classroom experience as generally positive compared to $70 \%$ for traditional students (see Figure 3). It is not necessarily the case however that this was due solely to instructional method. Several factors may have contributed to this result, including: (a) small sample size; (b) completion of only oneself-assessment during the semester; (c) the majority of IB students specifically chose their lab class (see Figure 5, question 14); and (d) all three IB classes were taught by the same instructor, while three different instructors taught the four traditional classes (see Figure 2, question 8). Of all 117 students, nearly $70 \%$ or greater (see Figure 1) were confident in their basic lab skills; with the notable exception of listing five essential elements of a lab report. At GMU, physics students learn to write lab reports during their first semester and are required to begin writing formal reports during their second semester. It is highly unlikely that the majority of students could not name the elements of a lab report. It is plausible that, while very few Likert questions were left blank, students simply did not take the time to carefully consider and complete responses to the short answer questions. Although IB students expressed more enthusiasm for completing experiments, less than $50 \%$ of all students were enthusiastic about completing experiments in Physics 261 (see Figure 2, question 7). While it is reasonable to expect physics majors to be enthusiastic about experimentation, $90 \%$ of the students taking Physics 261 were not physics majors (see Figure 3). One of the major challenges faced by instructors is to help non-physics majors understand the applicability of the material to other fields, such as engineering. Overall, self-assessment results show substantial room for improvement in both perceptions and learning gains of all students.

BEMA scores, for the Spring 2015 Semester, were low for both IB and traditional classes, which could indicate an issue with student comprehension, or simply that students did not take the test seriously, or that the 
test was in fact too conceptually challenging for introductory level EM students. Preliminary results from the Fall 2015 Semester show similar BEMA scores. To encourage students to put effort into the assessment, extra credit was given based on the number of correct answers and yet scores remained low. Pollock and Finkelstein (2014) at Colorado University (CU) achieved an average gain factor of 57\% with comparable STDEV for a large scale study $(N=9,000)$; noting that $50 \%$ of their students for whom scores were available averaged 650 on the math portion of the SAT. According to SATSCORES (2015), average SAT math scores for GMU students range from 520-630. These data suggest that GMU students are likely not as well prepared. This is not surprising since $\mathrm{CU}$ is a world-class school for physics (Graduate Admissions CU, 2015), while GMU is ranked 116th (Physics Schools, 2015) in the United States. Perhaps, the BEMA is not the best tool for assessing students without the CU students' math skills surmised from the SAT scores; creation of a custom EM assessment could be useful in targeting problem areas for GMU students.

Research did not conclusively show, as hoped, that the IB format is superior to the traditional format for laboratory instruction. What was demonstrated by this project is that the IB method is at a minimum comparable to the traditional, i.e., there is no negative impact evident from implementation of the IB method and it may improve general student perceptions of the laboratory experience. As a result of this project and other currently available PER, GMU has begun teaching all sections of Physics 261 in an integrated format. By combining traditional and IB methods, it is hoped that students will reap the benefits of both. To monitor progress, a self-assessment survey (very similar to the one used here) as well as an EM assessment (currently the BEMA) will continue to be administered every semester. It is imperative to the validity and efficacy of PER that all research on instructional methods be published. An erroneous bias toward IB labs (or some other instructional format) could develop if researchers fail to publish negative and/or inconclusive results along with the positive. Continued contributions to the ever-expanding body of PER will only benefit both students and instructors.

\section{References}

Bao, L. (2006). Theoretical comparisons of average normalized gain calculations. American Journal of Physics, 74(10). Retrieved from http://dx.doi.org/10.1119/1.2213532

Brickman, P., Gormally, C., Armstrong, N., \& Hallar, B. (2009). Effects of inquiry-based learning on students' science literacy skills and confidence. International Journal for the Scholarship of Teaching and Learning, 3(2). Retrieved from http://digitalcommons.georgiasouthern.edu/ij/sotl-vol/iss2/16

Cahill, M. J., Hynes, K. M., Trousil, R., Brooks, L. A., McDaniel, M. A., Repice, M., ... Frey, R. F. (2014). Multiyear multi-instructor evaluation of a large-class interactive-engagement curriculum. Physics Review Special Topics Physics Education Research, 10(2). Retrieved from http://link.aps.org/doi/10.1103/PhysRevSTPER.10.020101

Deters, K. M. (2005). Student opinions regarding inquiry-based labs. Journal of Chemical Education, 82(8). Retrieved from http://pubs.acs.org/doi/pdfplus/10.1021/ed082p1178

Ding, L., Chabay, R., Sherwood, B., \& Beichner, R. (2006). Evaluating an electricity and magnetism assessment tool: Brief electricity and magnetism assessment. Physics Review Special Topics Physics Education Research, 2(1). Retrieved from http://link.aps.org/doi/10.1103/PhysRewSTPER.2.010105

Ding, L. (2014). Seeking missing pieces in science concept assessments: Reevaluating the brief electricity and magnetism assessment through Rasch analysis. Physics Review Special Topics Physics Education Research, 10(1). Retrieved from http://link.aps.org/doi/10.1103/PhysRevSTPER.10.010105

Etkina, E., Murthy, S., \& Zou, X. (2006). Using introductory labs to engage students in experimental design. American Journal of Physics, 74(979). Retrieved from http://dx.doi.org/10.1119/1.2238885

Eylon, B., \& Bagno, E. (2006). Research design model for professional development of teachers: Designing lessons with physics education research. Physics Review Special Topics Physics Education Research, 2(2). Retrieved from http://link.aps.org/doi/10.1103/PhysRewSTPER.2.020106 
Gaffney, J. D. H. (2013). Education majors' expectations and reported experiences with inquiry based physics: Implications for student affect. Physics Review Special Topics Physics Education Research, 9(1). Retrieved from http://link.aps.org/doi/10.1103/PhysRewSTPER.9.010112

Graduate Admissions, Colorado University. (2015). Academic ranking of world universities. Retrieved from http://www.colorado.edu/admissions/graduate/about/rankings/list

Hake, R. R. (1998). Interactive-engagement versus traditional methods: A six-thousand-student survey of mechanics test data for introductory physics courses. American Journal of Physics, 66(1). Retrieved from http://dx.doi.org/10.1119/1.18809

Lindsey, B. A., Hsu, L., Sadaghiani, H., Taylor, J. W., \& Cummings, K. (2012). Positive attitudinal shifts with the physics by inquiry curriculum across multiple implementations. Physics Review Special Topics Physics Education Research, 8(1). Retrieved from http://link.aps.org/doi/10.1103/PhysRewSTPER.8.010102

Lindsey, B. A., \& Nagel, M. L. (2015). Do students know what they know? Exploring the accuracy of student self-assessments. Physics Review Special Topics Physics Education Research, 11(2).

McDermott, L. C. (2001). Oersted Medal Lecture 2001: "Physics education research-the key to student learning." American Journal of Physics, 69(1127). Retrieved from http://dx.doi.org/10.1119/1.1389280

Physics Schools. (2015). George Mason University physics ranking. Retrieved from http://physics-schools.com/george-masonuniversity

Plomer, M., Jessen, K., Rangelov, G., \& Meyer, M. (2010). Teaching physics in a physiologically meaningful manner. Physics Review Special Topics Physics Education Research, 6(2). Retrieved from http://ink.aps.org/doi/10.1103/PhysRew STPER.6.020116

Pollock, S. J., \& Finkelstein, N. (2014). Impacts of curricular change: Implications from 8 years of data in introductory physics. Retrieved from http://www.colorado.edu/per/research/papers-author

SATSCORES. (2015). Math SAT scores. Retrieved from http://www.satscores.us/sat_scores_by_college.asp?College_ID=232186

Seymour, E., Wiese, D. J., Hunter, A., \& Daffinrud, S. M. (2000, March 27). Creating a better mousetrap: On-line student assessment of their learning gains. Paper presented to The National Meetings of the American Chemical Society Symposium, “Using Real-World Questions to Promote Active Learning," San Francisco, USA.

Sundberg, M. D., \& Armstrong, J. E. (1993). The status of laboratory instruction for introductory biology laboratories in U.S. universities. The American Biology Teacher, 55(3), 144-146. Retrieved from http://doi.org/10.2307/4449610

Sundberg, M. D., Armstrong, J. E., \& Wischusen, E. W. (2005). A reappraisal of the status of introductory biology laboratory education in U.S. colleges and universities. The American Biology Teacher, 67(9), 525-529.

Thacker, B., Dulli, H., Pattillo, D., \& West, K. (2014). Lessons from a large-scale assessment: Results from conceptual inventories. Physics Review Special Topics Physics Education Research, 10(2). Retrieved from http://link.aps.org/doi/10.1103/PhysRewSTPER.2.10.020104

Yoder, G., \& Cook, J. (2014). Rapid conversion of traditional introductory physics sequences to an activity-based format. Journal of STEM Education, 15(2).

Zwicki, B. M., Hirokawa, T., Finkelstein, N., \& Lewandowski, H. J. (2014). Epistemology and expectations survey about experimental physics: Development and initial results. Physics Review Special Topics Physics Education Research, 10(1). Retrieved from http://link.aps.org/doi/10.1103/PhysRewSTPER.10.010120 
Appendix: Physics 261 Assessment Spring 2015

Physics 261 Assessment Spring 2015 Personal Number

Please circle the most appropriate answer to the following questions, or explain in your own words (where applicable).

Presently, I can ...

Assemble a simple circuit, using a breadboard, wires, resistors and capacitors.

\begin{tabular}{|l|l|l|l|l|l|}
\hline Not at all & A little & Fairly well & Well & Very well & Skill mastered \\
\hline
\end{tabular}

Use Excel to create a fully annotated graph, with axes labels and title.

\begin{tabular}{|l|l|l|l|l|l|}
\hline Not at all & A little & Fairly well & Well & Very well & Skill mastered \\
\hline
\end{tabular}

Develop a strategy to solve problems faced by my lab group.

\begin{tabular}{|l|l|l|l|l|l|}
\hline Not at all & A little & Fairly well & Well & Very well & Skill mastered \\
\hline
\end{tabular}

Write a detailed lab report that contains an introduction with hypothesis and background material, and the following essential sections:

How much has taking Physics 261 improved your skills in the above areas?

\begin{tabular}{|l|l|l|l|l|l|}
\hline Not at all & A little improved & $\begin{array}{l}\text { Somewhat } \\
\text { improved }\end{array}$ & Improved & Well improved & $\begin{array}{l}\text { Significantly } \\
\text { improved }\end{array}$ \\
\hline
\end{tabular}

Presently I am ...

Confident that I understand the physics concepts I have learned in this class.

\begin{tabular}{|l|l|l|l|l|l|}
\hline Not at all & A little & Fairly confident & Confident & Very confident & Extremely confident \\
\hline
\end{tabular}

Enthusiastic about constructing experiments in my physics lab class.

\begin{tabular}{|l|l|l|l|l|l|}
\hline Not at all & A little & Fairly enthusiastic & Enthusiastic & Very enthusiastic & $\begin{array}{l}\text { Extremely } \\
\text { enthusiastic }\end{array}$ \\
\hline
\end{tabular}

Comfortable asking my instructor or TA questions during lab class.

\begin{tabular}{|l|l|l|l|l|l|}
\hline Not at all & A little & Fairly comfortable & Comfortable & Very comfortable & $\begin{array}{l}\text { Extremely } \\
\text { comfortable }\end{array}$ \\
\hline
\end{tabular}

Confident in my ability to successfully complete all lab experiments in this course.

\begin{tabular}{|l|l|l|l|l|l|}
\hline Not at all & A little & Fairly confident & Confident & Very confident & Extremely confident \\
\hline
\end{tabular}

I am in the habit of ...

Working on and attempting to complete my assignments at least 24 hours before they are due.

\begin{tabular}{|l|l|l|l|l|l|}
\hline Never & Sometimes & Fairly often & Often & Very often & Always \\
\hline
\end{tabular}

Reading assigned materials before coming to class.

\begin{tabular}{|l|l|l|l|l|l|}
\hline Never & Sometimes & Fairly often & Often & Very often & Always \\
\hline
\end{tabular}

Connecting key ideas I learn in class to real world situations.

\begin{tabular}{|l|l|l|l|l|l|}
\hline Never & Sometimes & Fairly often & Often & Very often & Always \\
\hline
\end{tabular}


Currently, in my academic career ...

I am pursuing a degree in:

\begin{tabular}{|l|l|l|l|l|l|}
\hline Physics & Math & $\begin{array}{l}\text { ECE or Bio } \\
\text { Engineer }\end{array}$ & $\begin{array}{l}\text { Civil or systems } \\
\text { engineer }\end{array}$ & $\begin{array}{l}\text { Other area of } \\
\text { science }\end{array}$ & Other non-science \\
\hline
\end{tabular}

Please circle the statement that corresponds to your choice of lab section:

I specifically chose the Traditional 261 lab class (not attached to the active and collaborative learning lecture section).

I specifically chose this lab class, because I am taking PHYS 260002 (the active and collaborative student learning section) with Dr. Dworzecka.

I chose this class because it fit into my schedule.

What is your (estimated) current cumulative GPA?

\begin{tabular}{|l|l|l|l|l|l|}
\hline 2.0 or less & 2.1 to 2.6 & 2.7 to 3.0 & 3.1 to 3.5 & 3.5 to 3.7 & Above 3.7 \\
\hline
\end{tabular}

My overall impression of this lab class is:

\begin{tabular}{|l|l|l|l|l|l|}
\hline Very negative & Negative & Somewhat negative & Somewhat positive & Positive & Very positive \\
\hline
\end{tabular}

\section{Comment (optional):}

Please comment on what you have learned in this laboratory. Do you hope to retain all/most/some of what you have learned this semester? 